\title{
RESÍDUOS SÓLIDOS DA CONSTRUÇÃO CIVIL
}

Gabriela Candeo Zanetti ${ }^{1}$, Karen Staquecini Martines ${ }^{1}$, Maria Eunice Carvalho Tosello ${ }^{1}$, Rebeca Delatore Simões ${ }^{2}$

${ }^{1}$ Universidade do Oeste Paulista - UNOESTE, Curso de Arquitetura e Urbanismo. ${ }^{2}$ Mestrado em Meio Ambiente e Desenvolvimento Regional - MMADRE, Presidente Prudente, SP. E-mail: karenstaquecini@gmail.com

\section{RESUMO}

Após a industrialização, ocorreu a ampliação de produção de resíduos sólidos pelas sociedades urbanas. Esse aumento faz com que muitas vezes não haja local adequado para o descarte, ocasionando problemas de saúde e ambiental. Dentre os vários tipos de resíduos, o da construção civil possui um enorme volume que poderia ser reutilizado. Deste modo, o artigo visa a discutir técnicas corretas para separação em canteiro de obras e o incentivo a sua aplicação em reutilização e reciclagem dos materiais. Busca-se demonstrar métodos atuais e a correção dos impactos por melhorias de limpeza. É importante estimular cada vez mais a população a colaborar com o processo de reciclagem.

Palavras-chave: Resíduos, construção civil, lixo, reciclagem e reutilização.

\section{SOLID WASTE OF CONSTRUCTION}

\begin{abstract}
After industrialization, the expansion of production of solid waste occurdded by urban societies. This increase means that often there is no suitable place for disposal, causing health and environmental problems. Among the various types of waste, the construction has a huge volume that could be reused. Thus, this paper has the objetive to discuss the correct techniques for separation in construction site and encouraging their application in reuse and recycling of materials. The target is to demonstrate current methods and correction of impacts by cleaning improvements. It is important to increasingly encourage the population to collaborate with the recycling process.
\end{abstract}

Keywords: Waste, construction, garbage, recycling and reuse. 


\section{INTRODUÇÃO}

A disposição inadequada dos resíduos compromete a paisagem local; o trafego de pedestres e veículos; provoca assoreamento de rios, córregos e lagos; o entupimento da drenagem urbana, acarretando enchentes; além de servirem de pretexto para o depósito irregular de outros resíduos não inertes, propiciando o aparecimento e a multiplicação de vetores de doenças, arriscando a saúde da população.

Tudo o que produzimos e consumimos mundialmente gera resíduos sólidos, que são materiais supérfluos ou sem utilidade que acabam sendo descartados. Conforme relatório do World Bank, 2015, anualmente são produzidos 1,3 bilhões de toneladas de lixo. Segundo esses dados, só os Estados Unidos produzem mais de 2,5Kg de lixo por pessoa em um único dia.

A maior quantidade de lixo, segundo Waldman,2011 é gerada através da pecuária, com ossadas, carcaças, embalagens de remédios, entre outros, resultando em $39 \%$ do lixo mundial. Logo em seguida, com 38\% são lixos produzidos com a mineração, $19 \%$ com a agricultura, o Industrial fica com $4 \%$, os resíduos da construção civil em 3\%, e os resíduos urbanos com 2,5\%. Os resíduos urbanos se dividem em lixo hospitalar, podas de árvores, eletroeletrônicos, papel, plástico, papelão, pneus, restos de alimentos, etc, e mesmo assim, os resíduos da construção civil possuem porcentagem maior de lixo produzido.

De acordo com a Associação Brasileira para Reciclagem de Resíduos da Construção Civil e Demolição (ABRECON), atualmente na Europa há um desperdício equivalente a 200 milhões de toneladas de concreto, pedras e recursos minerais valiosos (LAGUETTE, 1995). Já no Brasil, são jogados fora oito bilhões de reais por ano, devido à falta de reciclagem, sendo que $70 \%$ desses resíduos poderiam ser reciclados. Calcula-se que uma obra no Brasil gere três vezes mais resquícios do que na União Europeia.

Segundo o CONAMA, o gerador dos resíduos é responsável pela sua reciclagem ou disposição final, proibindo seu envio a aterros sanitários. Esses resíduos eram descartados de maneiras errôneas, sem a preocupação com o meio ambiente. Devido a isso, foi estipulada a lei no 12.305, de 02 de agosto de 2010, a qual exige do poder público um local apropriado para o descarte do entulho.

Estudos elaborados no Brasil desde a década de 1980, já dão impulso suficiente para a difusão dos processos de reciclagem como alternativa de destinação dos resíduos de construção civil para um elevado número de centros urbanos. Porém certamente precisam ser aprofundados e ampliados, para possibilidades de novas técnicas de reutilização, para pequenos e grandes centros (MAGALHÃES et. al., 2010).Segundo dados do Sindicato da Indústria da Construção Civil do 
Estado de São Paulo (SINDUSCON-SP, 2005) a atividade da construção civil gera a parcela predominante do volume total dos resíduos sólidos urbanos produzidos nas cidades paulistanas.

Dessa forma, a metodologia empregada para a elaboração deste artigo consistiu na revisão bibliográfica sobre o tema, pesquisas em trabalhos científicos desenvolvidos nessa área, em coleta de informações sobre as normas e leis vigentes, enfocando as suas possíveis aplicações como reutilização e reciclagem.

Neste contexto, o artigo tem por objetivo levantar informações quanto aos resíduos sólidos da construção civil (RCC), para contribuir com dados e informações que possam direcionar a reutilização e reciclagem, fornecendo informações sobre a maneira correta de descarte dos resíduos da construção civil, aprofundando o conhecimento sobre os métodos e técnicas utilizadas atualmente, divulgando a conscientização do aproveitamento dos resíduos em prol da minimização do impacto ao meio ambiente.

\section{TIPOS DE LIXO}

De acordo com a ABNT - NBR 10004/2004, os resíduos sólidos são todos os materiais resultantes de processo de produção, transformação, utilização ou consumo de fins humanos ou animais, não mais utilizados. Sua classificação segundo a norma está relacionada com a forma de origem e seus constituintes. Os resíduos perigosos podem apresentar riscos para a sociedade ou para o meio e apresentam uma das seguintes características: inflamabilidade, corrosividade, reatividade, toxicidade e/ou patogenicidade.

Os resíduos não perigosos são aqueles que não apresentam nenhum risco acima citado, porém se divide em dois: os inertes, que quando submetidos ao contato com água destilada, a temperatura ambiente, não sofram alterações em seus constituintes, exceto na cor, turbidez, dureza e sabor e os não inertes, que não se enquadram em nenhum dos outros dois, e podem apresentar características como biodegradabilidade, combustibilidade e solubilidade em água.

A norma estabelece que os resíduos podem ser separados de acordo com a origem e de acordo com o tipo, se classificando em resíduo reciclável e resíduo não reciclável ou rejeito. E quanto à composição química os resíduos podem ser classificados em orgânicos, persistentes e não persistentes, e inorgânicos. Os poluentes orgânicos persistentes (POP) são compostos orgânicos perigosos com norma internacional para seu controle, e os poluentes orgânicos não persistentes são, por exemplo, óleos, solventes e detergentes. 


\section{RESÍDUOS NA CONSTRUÇÃO CIVIL}

Os resíduos na construção civil são provenientes de novas construções, reformas, reparos e demolições de obras de construção, como os resultantes da preparação e da escavação de terrenos. A Resolução 307/ CONAMA classifica os resíduos da construção civil em quatro grupos: Classe A - resíduos reutilizáveis ou recicláveis como agregados; Classe B - resíduos recicláveis para outras destinações, como plásticos, vidros e outros; Classe C - resíduos para os quais não foram desenvolvidas tecnologias ou aplicações economicamente viáveis que permitam a sua reciclagem/recuperação, como gesso; Classe D - resíduos perigosos oriundos do processo de construção ou contaminados.

Já a NBR 10004/2004 classifica os resíduos sólidos quanto aos riscos ao meio ambiente e à saúde pública. Podem ser classificados em: Resíduos classe I - Perigosos, são resíduos que apresentam periculosidade, podendo ser inflamáveis, corrosivos, reativos, tóxicos ou patogênicos; Resíduos Classe II - Não perigosos; são Resíduos de papel e papelão, de plástico polimerizado, de borracha, madeira, bagaço de cana, etc.; Resíduos Classe II A - Não inertes, resíduos que podem ter características biodegradáveis, combustibilidade ou de solubilidade em água; Resíduos Classe II B - Inertes; resíduos que não apresentam nenhum de seus constituintes solubilizados a concentrações superiores aos padrões de potabilidade de água, excetuando-se aspecto, cor, turbidez, dureza e sabor (BRASIL, 2004).

Os Resíduos da Construção e Demolição (RCD) são considerados responsáveis por $50 \%$ do esgotamento de áreas dos aterros de Resíduos Sólidos Urbanos (ANGULO et al, 2003). São classificados como construções informais que abrangem atividades de reforma e ampliação onde os coletores dispõem estes resíduos em áreas não regularizadas pelo poder público local, e essas áreas que destinam os RCD acabam atraindo todo e qualquer tipo de resíduo não possuindo captação rotineira. O problema da deposição inadequada do RCD é que compromete a paisagem do local; o tráfego de pedestres e de veículos; provoca o assoreamento de rios, córregos e lagos; o entupimento da drenagem urbana, acarretando em enchentes; além de servirem de pretexto para o depósito irregular de outros resíduos não inertes, propiciando o aparecimento e a multiplicação de vetores de doenças, arriscando a saúde da população vizinha.

Elevados custos despendidos para a realização da limpeza, principalmente em virtude dos equipamentos utilizados no recolhimento dos mesmos serem totalmente inadequados a esse tipo de serviço (PINTO, 2001 apud CABRAL; MOREIRA, 2011, p.17 ). Além disso, essa prática não promove a sustentabilidade, uma vez que não incentiva a redução, reutilização ou reciclagem desses resíduos. Infelizmente, um grande número de cidades brasileiras se encontra nesta 
situação de promoção da gestão dos resíduos de maneira emergencial (CABRAL; MOREIRA, 2011, p.17).

O Art. 4 da Resolução 307 do CONAMA enfatiza que os RCD não podem ser dispostos em aterros de resíduos domiciliares, em áreas de "bota fora", em encostas, corpos d'água, lotes vagos e em áreas protegidas por Lei. Para os RCD Classe A, a disposição final adequada é exclusivamente em aterro de inertes, sendo que estes resíduos devem, preferencialmente, ser reciclados.

\section{A. RECICLAGEM}

Processo de transformação de resíduos da construção civil que envolve a alteração das propriedades físicas ou físico-químicas dos mesmos, tornando-os insumos destinados a processos produtivos. As vantagens da reciclagem são a preservação de recursos naturais reduzindo o impacto ambiental; redução da necessidade de áreas para aterro devido à redução do volume de resíduos a serem depositados e a geração de empregos com o negócio gerado com a reciclagem. De acordo com o IBGE (2000), apenas doze dos 5.507 Municípios brasileiros possuíam centrais de reciclagem de resíduos sólidos da construção civil em operação.

\section{B. REUTILIZAÇÃO}

Aproveitamento de um resíduo, uma ou mais vezes, na sua forma original, sem beneficiamento, ou seja, sem transformação física ou físico-química, assegurado, quando necessário, o tratamento destinado ao cumprimento dos padrões de saúde pública e meio ambiente.

\section{SEGREGAÇÃO}

Consiste na triagem dos resíduos da construção civil, segundo a classificação exigida por norma regulamentadora. Deverá ser feita no local de origem, em pilhas próximas ao local de geração, e ao final do dia realizar a segregação assegurando sua reutilização ou reciclagem. É importante que os funcionários sejam treinados e qualificados para a execução do serviço. Caso ocorra a contaminação do resíduo, sua reutilização será comprometida; uma vez separados adequadamente contribuem também para a limpeza e organização da própria obra.

\section{REJEITO}

Os rejeitos são resíduos sólidos que, depois de esgotadas todas as possibilidades de tratamento e recuperação por processos tecnológicos disponíveis e economicamente viáveis, não 
apresentem outra possibilidade que não a disposição final ambientalmente adequada (Lei Federal no $12.305,2010)$.

\section{SEPARAÇÃO NO CANTEIRO}

A implantação da coleta seletiva dos resíduos consiste na mobilização das pessoas que trabalham nas obras através de palestras, fixação de cartazes, mensagens e outros meios apropriados e para o descarte dos resíduos utilizados. Pode-se reutilizar latas e latões para a separação do lixo; bombonas com etiquetas adesivas de tamanho A4-ABNT com cores padrão utilizado para a identificação de resíduos em coleta seletiva; bags de ráfia que são utilizadas para armazenamento de serragem, EPS (isopor), restos de uniformes, botas, tecidos, panos e trapos, plásticos, embalagens de papelão etc ; baias ou depósitos fixos, utilizadas para depósito de restos de madeira, ferro, aço, arames, EPS, serragem etc; e também é comum o emprego de caçamba estacionária.(apud Guia para Elaboração de Projeto de Gerenciamento de Resíduos da Construção Civil, 2009)

\section{GESTÃO PÚBLICA DOS RESÍDUOS DA CONSTRUÇÃO CIVIL EM PRESIDENTE PRUDENTE}

Segundo Pinto (2008), no município de Presidente Prudente, a disposição do lixo ainda é realizada de forma precária e inadequada. A maioria dos resíduos descartados poderia ser reutilizado na construção civil, trazendo benefício ambiental, benefícios econômicos, minimizando gastos da gestão pública com os resíduos; e benefícios sociais, como o desenvolvimento de novos empregos para a cidade.

Segundo a Companhia Prudentina de Desenvolvimento (PRUDENCO), são gerados na cidade cerca de 235 toneladas de resíduos sólidos por dia, e a coleta e transporte dos RCC são realizados por meio da contratação de empresas particulares. Atualmente são quatro empresas que operam no município.

Juntando os serviços realizados pelas quatro empresas que atuam no município, que coletam resíduos provenientes de todas as atividades da construção civil tem-se uma média de 1.367 coletas de caçambas por mês. Considerando-se que cada caçamba comporta até $5 \mathrm{~m}^{3}$ e que o peso específico aparente do entulho é de $1.300,0 \mathrm{~kg} / \mathrm{m}^{3}$ (MONTEIRO et al, 2001), tem-se um volume igual a $6.835,0 \mathrm{~m}^{3} / \mathrm{mês}$ e peso igual a $8.885 .500 \mathrm{~kg} / \mathrm{mês}$ ou $8.885,5$ toneladas de entulho por mês. Ao final de um ano a cidade produz 106.626 toneladas de entulho, o que significa uma geração de 0,52 t/hab./ano ou cerca de 4 vezes maior do que a estimativa apresentada anteriormente (PINTO, 2008, p. 81). 
De acordo com PINTO, 2008, os resíduos da construção civil de Presidente Prudente podem ser dispostos em duas áreas regularizadas pela prefeitura municipal. São elas: o lixão, localizado no Distrito Industrial, e uma área próxima à escola da rede SESI, na Rua José Alves da Paixão, na passagem da Rua Ademar de Barros. No entanto, há vários pontos da cidade onde são depositados lixos de maneira irregular, como mostra a figura 1.

A partir da Lei 12.305, 2010, a Prefeitura de Presidente Prudente publicou que elaboraria e implantaria um Plano de Gerenciamento Integrado de Resíduos de Construção e Demolição para o município, contemplando todo o aspecto socioambiental, sanitário, econômico, jurídico, operacional e administrativo. Permitindo avaliar aspectos quantitativos dos RCD produzidos no município para a obtenção de um perfil mais completo que possibilitará um gerenciamento mais adequado da geração, coleta, reciclagem e disposição final.

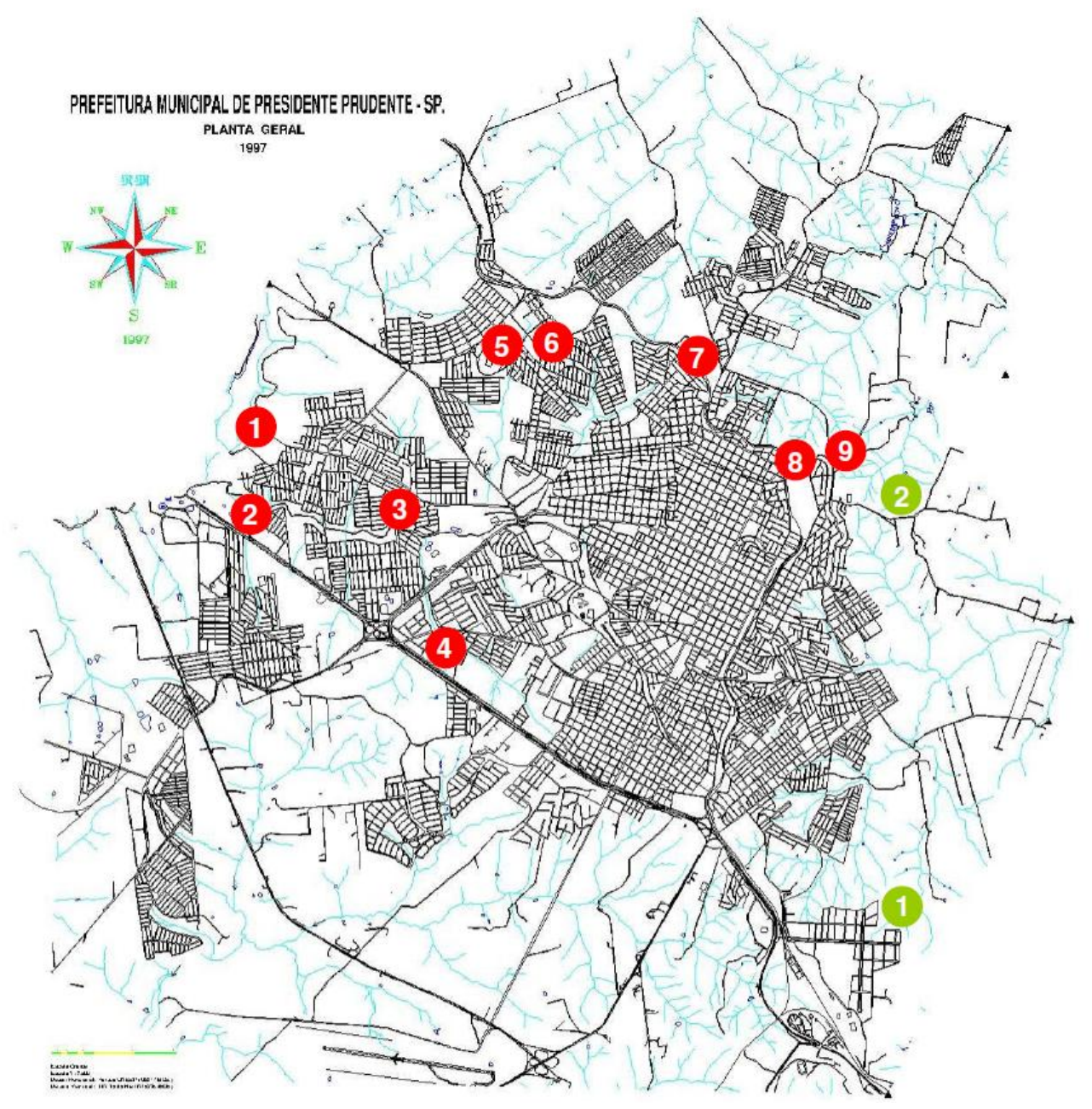


LEGENDA

Áreas autorizadas

1 Lixão, no Distrito Industrial

2 Propriedade da prefeitura perto da Escola SESI, Rua Dr. José Alves da Paixão

Áreas irregulares

(1) Balneário da Amizade e proximidades

APP do Córrego do Limoeiro, Bairro Jardim

(2) Vale do Sol

(3) APP do Córrego do Veado, Bairro COHAB e Jardim Santa Paula
(4) APP do Córrego do Veado, próximo da Av. Joaquim Constantino

(5) Av. Juscelino Kubitscheck, próximo ao Estádio Municipal Prudentão

(6) Av. Paulo Marcondes, Bairro Jardim Barcelona

(7) Rua Itaro Ikayanagui, próximo à Rua Amilcar Artoni

8 Rua Alvino Gomes Teixeira, próximo à Faculdade Toledo, Parque Furquim

9 Av. Dr. Ibrian Nobre, Próximo à Escola SESI, Bairro Parque Furquim

Figura 1. Localização dos locais de disposição de RCC em Presidente Prudente, 2008.

Fonte: Diagnóstico dos resíduos de construção civil em Presidente Prudente. Apud PINTO, 2008.

\section{CONCLUSÃO}

O atual processo linear com os resíduos da construção civil deve ser substituído por uma logística circular, de natureza sustentável. O incentivo a população deve ser constante e a instalação de eco pontos em locais de fácil acesso deve ser providenciada, não apenas para resíduos de construção, mas também para resíduos sólidos em geral. Dentro de cada obra, o exercício de separação, reciclagem e reaproveitamento diminui os impactos ambientais e os gastos exagerados com materiais. A separação dos materiais em caçambas, latões, e demais, facilitam o processo de limpeza e reutilização.

\section{REFERÊNCIAS}

ASSOCIAÇÃO BRASILEIRA DE NORMAS TÉCNICAS. Resíduos sólidos - classificação: NBR 10004. São Paulo, 2004.

BAPTISTA Jr., J. V.; ROMANEL, C. Sustentabilidade na indústria da construção: u0ma logística para reciclagem dos resíduos de pequenas obras. 2013. 11f. Tese (Doutorado em Engenharia Civil) Pontifícia Universidade Católica do Rio de Janeiro, Rio de Janeiro.

FERNANDEZ, J. A. B. Resíduos da Construção Civil. 2011. Disponível em: <http://www.cnrh.gov.br/projetos/pnrs/documentos/cadernos/02_CADDIAG_Res_Const_Civil.pdf $>$ Acesso em: 27 out. 2014.

GALEFFI, C. Quem produz mais lixo no mundo. Disponível em: <http://www.portalresiduossolidos.com/quem-produz-mais-lixo-no-mundo/> Acesso em: 19 mai. 2015.

INOVA. Ecoponto. Disponível em: <http://www.inovagsu.com.br/Ecoponto.asp> Acesso em: 15 jun. 2015. 
LIMA, R. S.; LIMA, R. R. R. Guia para Elaboração de Projeto de Gerenciamento de Resíduos da Construção 2 Civil. $2009 . \quad$ Disponível em: <http://www.cuiaba.mt.gov.br/upload/arquivo/cartilhaResiduos_web2012.pdf> Acesso em: 26 mai. 2015.

MINISTÉRIO PÚBLICO FEDERAL. "Diretrizes básicas para projetos de coleta seletiva e educação ambiental no âmbito do acordo mp/cesp". Presidente Prudente, 2011. Disponível em: <http://bacias.fct.unesp.br/residuos/diretrizesparaprojetosdecoletaseletivamunicipalfinal.pdf> Acesso em: 16 mai. 2015.

PINTO, C. A.Diagnóstico dos resíduos sólidos de construção civil no município de Presidente Prudente - SP. 2008. 167f. Trabalho de Conclusão de Curso (Graduação em Arquitetura e Urbanismo) - Faculdade de Ciências e Tecnologia,Universidade Estadual Paulista, Presidente Prudente.

PREFEITURA DO MUNICÍPIO DE PRESIDENTE PRUDENTE - SECRETARIA MUNICIPAL DE MEIO AMBIENTE. Plano de gerenciamento integrado dos resíduos sólidos de Presidente Prudente - SP. Presidente Prudente, 2012.

SEBRAE. Coleta e Reciclagem de Resíduos da Construção Civil. Disponível em: <http://sustentabilidade.sebrae.com.br/Sustentabilidade/Cartilhas/Coleta-e-Reciclagem-deResiduos-da-Constru\%C3\%A7\%C3\%A3o-Civil> Acesso em: 3 out 2014.

SINDUSCON-MG. Cartilha de gerenciamento de resíduos sólidos para a construção civil. Belo Horizonte, $2005 . \quad$ Diponível em: <http://www.unipacvaledoaco.com.br/ArquivosDiversos/Cartilha_Res\%C3\%ADduos\%20Constru\% C3\%A7\%C3\%A30\%20Civil.pdf> Acesso em: 03 out 2014.

SINDUSCON-SP. Gestão ambiental de resíduos da construção civil. São Paulo, 2005. Disponível em:

<http://www.sindusconsp.com.br/downloads/prodserv/publicacoes/manual_residuos_solidos.pdf > Acesso em: 26 mai. 2015.

SINDUSCON-SP. Resíduos da construção civil - E o estado de São Paulo. São Paulo, 2012. Disponível

em: <http://www.ambiente.sp.gov.br/cpla/files/2012/09/residuos_construcao_civil_sp.pdf > Acesso em: 03 out. 2014.

TAKENAKA, E. M. M. Políticas públicas de gerenciamento integrado de resíduos sólidos urbanos no município de Presidente Prudente - SP. 2008. 234f. Tese (Doutorado em Geografia) Faculdade de Ciências e Tecnologia, Universidade Estadual Paulista, Presidente Prudente.

WALDMAN, M. De onde vem o lixo produzido no mundo. Estadão, São Paulo, 29 set. 2011. Disponível em: <http://www.estadao.com.br/infograficos/de-onde-vem-o-lixo-produzido-nomundo,sustentabilidade,235040> Acesso em: 26 mai. 2015. 